\title{
Research on System Dynamic Modeling and Simulation of Chinese Supply Chain Financial Credit Risk from the Perspective of Cooperation
}

\author{
Yuanxiang Dong ${ }^{1}$, Chenjing $\mathrm{Hou}^{1}$, and Duo Zhao ${ }^{2}$ \\ ${ }^{1}$ School of Management Science and Engineering, Shanxi University of Finance and Economics, Wucheng \\ Road, Taiyuan, PR China \\ ${ }^{2}$ Department of Computer Science, The University of Hong Kong, Pok Fu Lam Road, Hong Kong, PR
}

China

Keywords: supply chain finance, cooperation, credit risk, system dynamics

\begin{abstract}
This paper, based on the theory of system dynamics, analyzed internal and external factors of Chinese supply chain financial credit risk and constructed the system dynamics model of Chinese supply chain financial credit risk, and utilized Vensim software to analyse the simulation results. The research shows that the financial market tends to be stable and the credit risk will reduce with the improvement of cooperation level, information sharing degree between enterprises and risk awareness of financial institutions in supply chain. The improvement of the credit level of core enterprises and SMEs can promote the stability of financial market and reduce supply chain financial credit risk, and the impact of core enterprises is more significant.
\end{abstract}

\section{INTRODUCTION}

Supply chain finance is a financing mode which draws support from the strength of core enterprises and based on the supply chain transaction relations and collateral to provide financial support for SMEs with weak funds. The application of supply chain finance can achieve the win-win situation of SMEs, core enterprises and financial institutions. Therefore, the supply chain finance that increases social welfare has been supported by the national policy. In February 2016, the Chinese government issued the policy paper of Opinions on the Financial Support for Steady Growth, Structural Adjustments and Increase of Efficiency of Industry.

It is noteworthy that supply chain finance- as a new financing model- has broken the bank's original credit model. Supply chain finance adopts the new model of "the main credit \& debt credit" to conduct credit inspection of SMEs, relaying on the future cash flow which is generated by which is generated by transaction and core enterprises credit. It can help improving the loan availability of SMEs, at the same time, provide a new method for the risk management of bank (Lei and Shi, 2014). Therefore, the essence of supply chain finance is credit financing, and the control of credit risk is still the key point of supply chain financial risk management.

The credit risk of supply chain finance has been paid wide attention. Most scholars focus on the credit risk prevention and credit rating model of supply chain finance. Zhu et al. (2016) proposed a new integrated ensemble machine learning (ML) method for predicting the credit risk of SMEs in supply chain finance; Zhu et al. (2016) constructed an LR model, an ANN model and three types of a two-stage hybrid model for predicting the credit risk of SMEs for financial institutions in the supply chain finance; Su and Zhong (2017) set up a SMEs' credit evaluation model based on the principle of variable weight with its dynamic data in order to improve the accuracy rate of credit risk assessment. In the supply chain, the supply chain financial credit risk is studied from different angles. Song et al. (2016) investigated that whether bridging tie or strong tie of SMEs in the supply chain can improve the availability of equity and debt capital through information sharing; Peura et al. (2016) offered a novel perspective by examining whether trade credit benefits suppliers through a horizontal channel.

From the existing literature, researches on supply chain financial credit risk mainly focus on credit rating and risk aversion of SMEs. However, supply chain finance is a complex system involving many enterprises, financial institutions and so on. There are few studies on the influencing factors of the credit risk and feedback mechanism of the complex system. The biggest difference between the supply chain finance and traditional trade finance and credit is that supply chain finance needs to find a large core enterprise in supply chain $(\mathrm{Li}, 2011)$, and then SMEs achieve the credit enhancement through the trading and guarantee relation with core enterprises. So the cooperation level between core enterprises and SMEs has a great influence on supply chain financial credit risk. This paper constructs a feedback system model which includes the level, number and success rate of cooperative relationship between core enterprises and SMEs. Using the system dynamics theory and Vensim software simulation, this paper studied the influencing factors and feedback mechanism of supply chain financial credit risk from the perspective of the supply chain system. Finally, this paper provides a systematic and feasible program to improve the security of entire financial system.

\section{ANALYSIS ON THE INFLUENCING FACTORS}

Credit is an important aspect of supply chain finance. The supply chain financial credit is based on core business credit and provides financial support for the 
supply chain. If supply chain is affected by some influencing factors, it will generate supply chain financial credit risk, and then quickly spread to the entire supply chain. It may even lead to the collapse of entire supply chain. So the study of influencing factors of Chinese supply chain financial credit risk plays an important role in reducing its credit risk.

Through the understanding of supply chain financial credit risk and the reference to literature on supply chain financial credit risk indexes, it can be concluded that the credit risk is characterized by multiple factors and complex nonlinearity. Based on the cooperation perspective, this paper analyses supply chain financial credit risk from two aspects: internal factors and external factors. As is shown in Figure 1.

The internal factors include the cooperation level of supply chain, core enterprises credit, SMEs credit, the risk awareness of financial institutions, information sharing degree. The external factors are mainly macro-environment and policy.

In supply chain financial models, the enterprises' cooperation level and the risk awareness of financial institutions affects supply chain financial credit risk. The credit level of enterprises is assessed by the bank through its own asset status, financial information and so on. Credit risk can promote financial institutions to raise risk awareness, and also react to supply chain financial credit risk. Information sharing can avoid asymmetric information between enterprises and reduce supply chain financial credit risk. In addition, the social macro-environment and policy will not change in the long run generally.

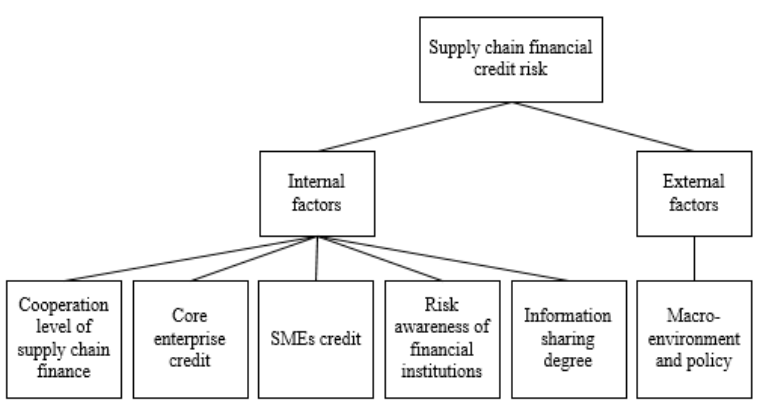

Figure 1: The influencing factors of Chinese supply chain financial credit risk.

\section{THE SYSTEM DYNAMICS MODEL}

\subsection{Determination of system boundary}

From the above analysis, it can be seen that influencing factors of supply chain financial credit risk are divided into internal factors and external factors. Due to external factors are regarded as the constant factors in the long run, the internal factors are considered as specific components of the system, namely the boundary of system.

In order to study the supply chain financial credit risk better, external factors are considered as constant quantity of the model. The changes affect the operation of system, but they are not involved in feedback loops of the system. The feedback loops of the system are mainly composed of internal factors.

\subsection{Causality of Chinese supply chain financial credit risk}

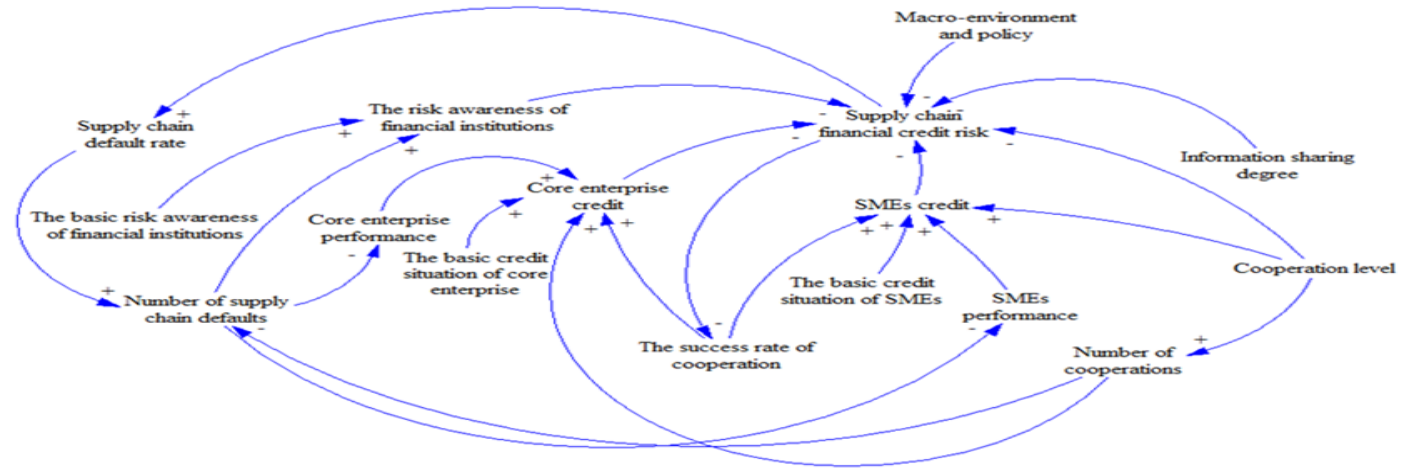

Figure 2: The causality graph of Chinese supply chain financial credit risk.

Causal loop diagram is an important tool to reflect feedback structure of a system, and it can express the dynamic causality of a system quickly. As the supply chain financial credit risk is affected by internal factors and external factors, the analysis of these factors is the primary task of system modeling. In this paper, the internal factors are further refined and interrelated, then the causality diagram of supply chain financial credit risk is formed. The symbol "+" indicates that the arrow tail factor has a positive influence on the factor of direction of the arrow, and the symbol "-" indicates that the arrow tail factor has a negative influence on the factor of direction of the arrow. As is shown in Figure 2:

There are 5 feedback loops in the causality graph on supply chain financial credit risk, including 4 positive feedback loops and 1 negative feedback loop. These 5 feedback loop diagrams reflect internal structure of the supply chain financial credit risk systematically. The main feedback loops are:

Positive feedback loop: (1) The loop is a positive feedback loop based on basic credit situation of core enterprises, including supply chain financial credit risk $\rightarrow$ supply chain default rate $\rightarrow$ number of supply chain defaults $\rightarrow$ core business performance $\rightarrow$ core business credit $\rightarrow$ supply chain financial credit risk. In supply chain financial credit risk system, the increase of supply chain financial credit risk results in the increase of supply chain default rate and the number of supply chain defaults. Then the core business performance is worse which can lead to reduction of the core business credit 
directly. Finally, supply chain financial credit risk will increase. (2) This positive feedback loop is mainly based on the basic credit situation of SMEs, including the supply chain financial credit risk $\rightarrow$ supply chain default rate $\rightarrow$ number of supply chain defaults $\rightarrow$ SMEs performance $\rightarrow$ SMEs credit $\rightarrow$ supply chain financial credit risk. In supply chain financial credit risk system, the increase of supply chain financial credit risk results in the increase of supply chain default rate. Then, the number of supply chain defaults will increase, and the performance of SMEs is worse which can lead to the reduction of SMEs credit directly. Finally, supply chain financial credit risk will increase. (3) The third positive feedback loop process includes the supply chain financial credit risk $\rightarrow$ the success rate of cooperation $\rightarrow$ core business credit $\rightarrow$ supply chain financial credit risk. In supply chain financial credit risk system, when the supply chain financial credit risk is reduced, the success rate of cooperation will increase, and the core enterprise credit increases. Finally, the supply chain financial credit risk will be reduced. (4) The fourth positive feedback loop process includes the supply chain financial credit risk $\rightarrow$ the success rate of cooperation $\rightarrow$ SMEs credit $\rightarrow$ supply chain financial credit risk. In the supply chain financial credit risk system, when the supply chain financial credit risk is reduced, the success rate of cooperation and the credit of SMEs will increase. Finally, supply chain financial credit risk will be reduced.

Negative feedback loop: The negative feedback loop process includes supply chain financial credit risk $\rightarrow$ supply chain default rate $\rightarrow$ number of supply chain defaults $\rightarrow$ risk awareness of financial institutions $\rightarrow$ supply chain financial credit risk. When supply chain financial credit risk increases, the supply chain default rate will increase. And the number of defaults will increase correspondingly, then the risk awareness of financial institutions will be increased. Finally, the supply chain financial credit risk will be reduced.

\subsection{The system dynamics flow diagram}

Based on the causal loop diagram, Venism is used as the software of modeling and simulation of system dynamics to plot the system dynamics flow diagram, as is shown in Figure 3:

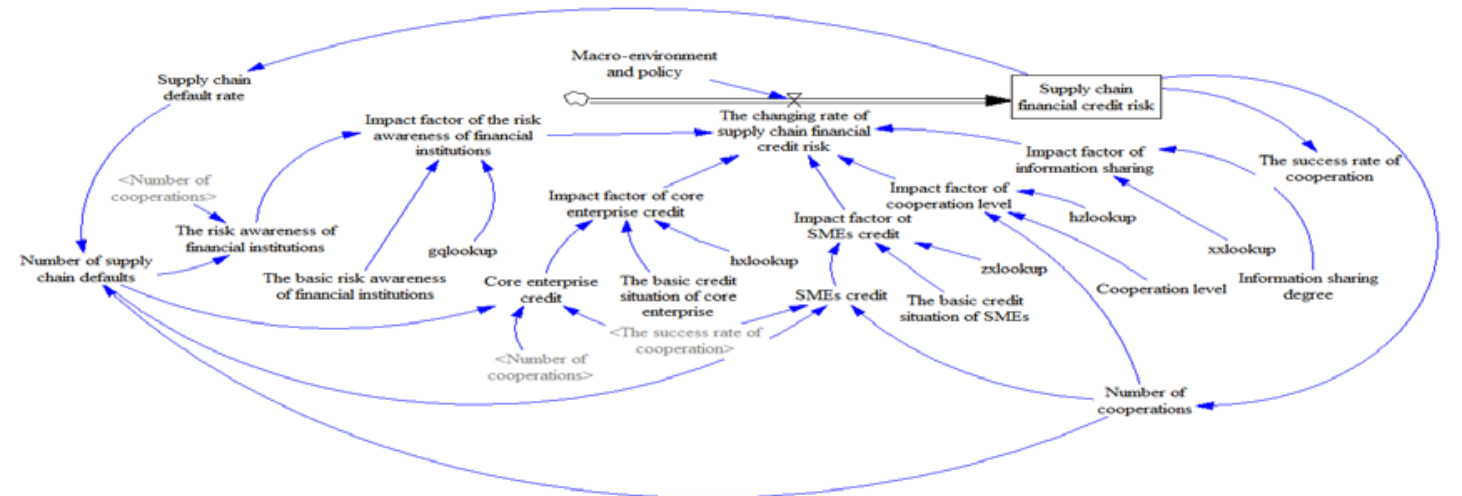

Figure 3: The system dynamics flow diagram of Chinese supply chain financial credit risk.

In Figure 3, the supply chain financial credit risk is the state stock of system and the result of the continuous accumulation of credit risk changes in supply chain finance. The changing rate of supply chain financial credit risk is the combination of inflows and outflows. The valve indicates that the supply chain financial credit risk is affected by other factors, and the cloud represents the system boundary. In Vensim, the table function is suitable for describing the nonlinear relationship between two variables. In this model, the variable value is adopted by linear interpolation method, including five table functions, namely, the table function of the risk awareness of financial institutions (jrlookup), the table function of core business credit (hxlookup), the table function of SMEs credit (zxlookup), the table function of cooperation level (hzlookup), and the table function of information sharing (xxlookup).

According to the system dynamics flow chart of supply chain financial credit risk, various risk factors are involved in the establishment of flow chart, so the equation of changing rate of supply chain financial credit risk is established. As is shown in equation (1):

$$
\frac{d E(t)}{d t}=J R(t)+H X(t)+Z X(t)+H Z(t)+X X(t)+H G
$$

The $E(t)$ represents the changing rate of supply chain financial credit risk; JR $(t)$ represents the changing rate of risk consciousness of financial institutions; HX (t) represents the changing rate of core business credit; ZX (t) represents the changing rate of SMEs credit; HZ (t) represents the changing rate of cooperation level; XX (t) represents the changing rate of information sharing; HG represents the macro-environment and policy, as a constant factor. In addition, based on data collection and analysis, the structural equations between variables can be established:

The changing rate of supply chain financial credit risk $=1$ / (the impact factor of core business credit + the impact factor of SMEs credit + the impact factor of the risk awareness of financial institutions + the impact factor of information sharing + the impact factor of cooperation level + the macro-environment and policy) (2)

The impact factor of the risk awareness of financial institutions = gqlookup (the risk awareness of financial institutions) +the risk awareness of financial institutions (3)

The risk awareness of financial institutions $=30$

The risk awareness of financial institutions $=10+$ (the number of cooperation - the number of supply chain 
defaults) $* 0.5+$ the number of supply chain defaults

Jrlookup[(0,0)-(600,10)],(3.669,0.0219),(51.376,0.03 07),(100.917,0.0526),(132.11,0.06578),(203.67,0.118),(2 33.028,0.1666),(332.11,0.2675),(379.817,0.4211),(420.1 83,0.5263),(466.055,0.6184),(508.257,0.6798),(554.128, 0.8465),(574.312,0.9474),(596.33,0.98658)

Description: the table function of the risk awareness of financial institutions (6)

The impact factor of core business credit $=$ hxlookup (core business credit) + the basic credit situation of core business $+20 \quad$ (7)

The core business credit $=20+$ the success rate of cooperation *the number of cooperation - the number of supply chain defaults * 0.3

The basic credit situation of core enterprises $=20(9)$

Hxlookup[(-400,0)-(60,10)],(-342.661,0.97807),(-28 5.168,0.916667),(-272.936,0.885), (-238.685,0.76158), $(-216.667,0.635),(-188.5,0.478),(-166.514,0.346),(-122.4$ 77,0.21),(-89.44,0.11),(-47.85,0.0833),(-9.93,0.07),(38.9, 0.04),(48.7,0.008) Description: the table function of core business credit (10)

The impact factor of SMEs credit = zxlookup (SMEs credit) + the basic credit situation of the SMEs

SMEs credit $=10+$ the success rate of cooperation * the number of cooperation -the number of supply chain defaults $* 0.02$

The basic credit situation of SMEs $=5$

Zxlookup[(0,0)-(20,10)],(10.0612,0.01315),(10.7645, 0.01315),(12.1713,0.057),(13.2416,0.07894),(14.0673,0. 1184),(15.2599,0.1798),(16.5749,0.359),(17.0642,0.482 4),(17.5841,0.609),(18.104,0.6973),(18.9908,0.789474),( 19.5413,0.9035),(19.8471,0.99122) Description: the table function of SMEs credit (14)

The impact factor of cooperation level = hzlookup (the number of cooperation) + cooperation level (15)

Cooperation level $=20$

Hzlookup[(0,0)-(100000, 10) ]

(733.945,0.0131),(5137.61,0.0307),(9724.77,0.057),( 11926.6,0.0745),(14862.4,0.1008),(17981.7,0.1359),(20 733.9,0.16228),(23853.2,0.1842),(29174.3,0.2236),(368 80.7,0.2807),(41834.9,0.324),(44587.2,0.381579),(4761 4.7,0.438),(52477.1,0.5526),(57798.2,0.644035),(61651. 4,0.7105),(64678.9,0.745),(72385.3,0.850877),(89449.5, 0.9868) Description: the table function of cooperation level

The impact factor of information sharing $=$ xxlookup (information sharing degree)

(18)

Xxlookup

[(0,0)-(400,100)],(1.223,0.4),(22.01,2.19),(31.804,5.7),(4 7.0948,12.2),(62.996,16.7),(83.792,20.17),(111.315,28.5 ),(130.275,33.7),(149.847,42.5),(162.691,51.7),(186.23,6 $0.9),(205.5,68.8),(238.532,82),(297.248,98)$

Description: the table function of information sharing (19)

Information sharing degree $=50$

Macro-environment and policy $=0.2$

The success rate of cooperation $=1 /$ supply chain

financial credit risk $* 8$

Initial value $=20$

Number of cooperation = supply chain financial credit risk / 1000

Number of supply chain defaults = supply chain default rate * the number of cooperation

Supply chain default rate = supply chain financial credit risk / 1000

\section{SYSTEM DYNAMICS SIMULATION RESULTS}

\subsection{The impact of supply chain cooperation on the system}

In order to observe the influence of cooperation level on supply chain financial credit risk, the cooperation level of this model is given three different values, which are 20, 50, 120, among which the value of higher cooperation level is higher. In this section, the impact of cooperation level on two aspects is simulated and compared, which are the changing rate of supply chain financial credit risk and supply chain default rate.

From Figure 4, 5, it can be seen that the higher cooperation level can reduce the changing rate of supply chain financial credit risk and supply chain default rate. So it can be concluded that improving the cooperation level of enterprises is helpful to deepen the trust between enterprises and make the whole supply chain run more smoothly.

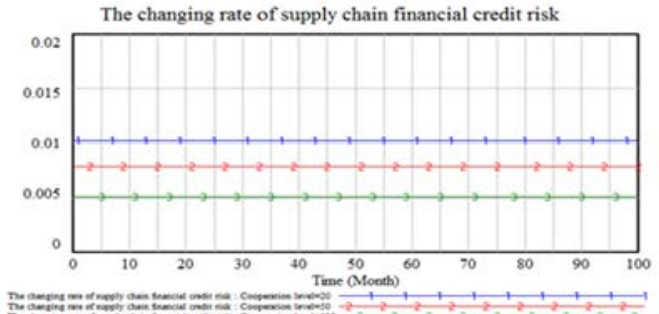

Figure 4: The influence of the cooperation level on the changing rate of supply chain financial credit risk.

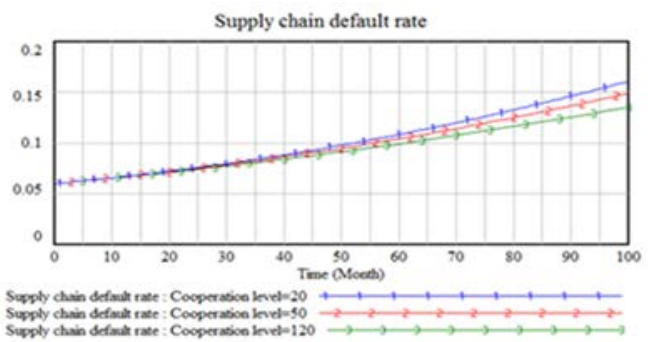

Figure 5: The influence of the cooperation level on the supply chain default rate.

\subsection{The impact of the basic risk awareness of financial institutions on the system}

In order to observe the impact of basic risk awareness of financial institutions on supply chain financial credit risk, the level of basic risk awareness of financial institutions is given three different values, namely 30,50 , 70 , among which the higher value indicates the higher basic risk awareness of financial institutions. In this section, the impact of the level of basic risk awareness of financial institutions on two aspects is simulated and compared, which are the changing rate of supply chain financial credit risk and the supply chain default rate.

It can be seen from Figure 6, 7 that the higher basic risk awareness of financial institutions can reduce the changing rate of supply chain financial credit risk and 
the supply chain default rate. So it can be concluded that raising the basic risk awareness of financial institutions can reduce the credit risk of the whole supply chain finance, and it helps to stabilize financial markets.

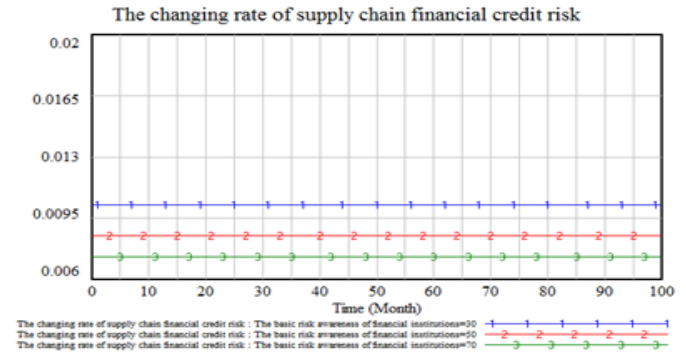

Figure 6: The influence of basic risk awareness of financial institutions on the changing rate of supply chain financial credit risk.

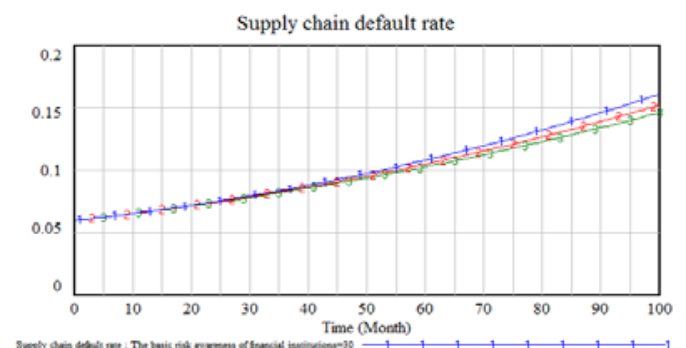

Ind

Figure 7: The influence of the basic risk awareness of financial institutions on the supply chain default rate.

\subsection{The comparison of the influence of basic credit status between core enterprises and SMEs on system}

In order to observe the influence of basic credit situation of core enterprises and SMEs on supply chain financial credit risk, the basic credit situation of them is given three different values. The core enterprises' are 20, 30, 40, and SMEs' are 5, 15, 25, among which the higher value means the basic credit level is higher. In this section, the influence of the change of enterprises' credit situation on two aspects is simulated and compared, which are the changing rate of supply chain financial credit risk and supply chain default rate.

From Figure 8, 9, 10, 11, it can be concluded that the credit situation of core enterprises and SMEs has the same direction effect on the changing rate of supply chain financial credit risk and supply chain default rate. And the higher the basic credit level is, the lower the risk changing rate and default rate is. And it can be seen from Figure 12 that the influence of the basic credit level of core enterprises on the changing rate of supply chain financial credit risk is more significant.

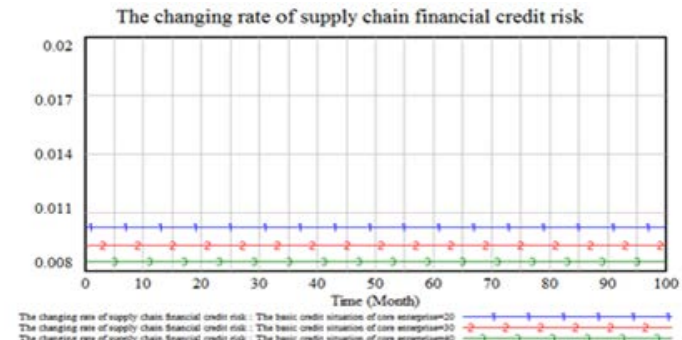

Figure 8: The influence of the basic credit situation of core enterprises on the changing rate of supply chain financial credit risk.



Figure 9: The influence of the basic credit situation of core enterprises on the supply chain default rate.

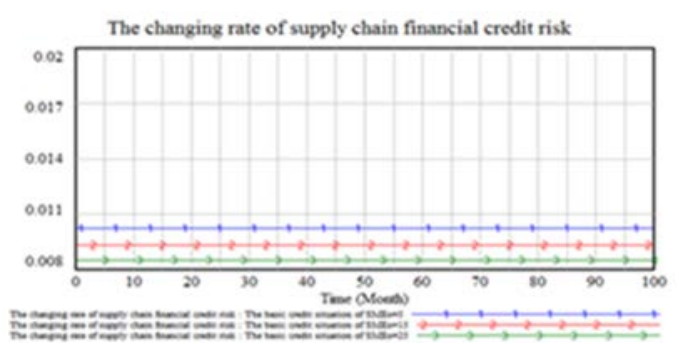

Figure 10: The influence of the basic credit situation of SMEs on the changing rate of supply chain financial credit risk.

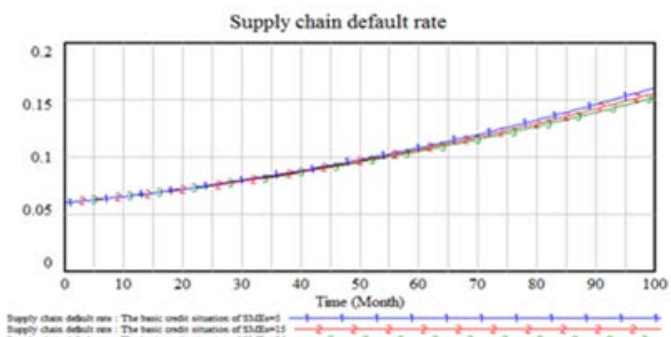

Figure 11: The influence of the basic credit situation of SMEs on the supply chain default rate.

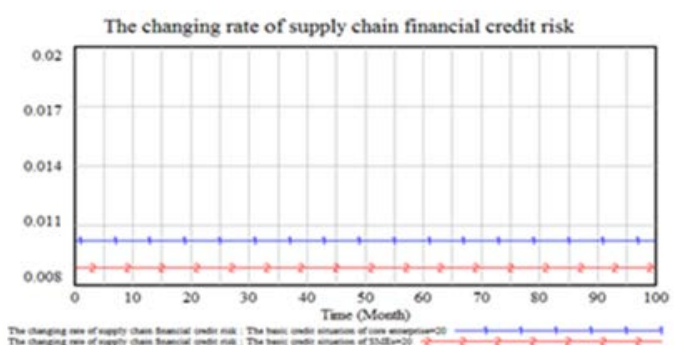

Figure 12: The comparison of the basic credit situation between core enterprises and SMEs.

\subsection{The influence of the change of information sharing degree on the system}

In order to observe the influence of information sharing degree on supply chain financial credit risk, the information sharing degree is given three different values, $30,50,70$, among which the higher value indicates the higher information sharing degree. In this section, the influence of the information sharing degree on two aspects is simulated and compared, which are the changing rate of supply chain financial credit risk and supply chain default rate.

It can be seen from Figure 13, 14 that improving the 
information sharing degree can reduce the changing rate of supply chain financial credit risk and supply chain default rate. So it can be concluded that the higher information sharing degree can make supply chain operation more smooth, and help reduce the information asymmetry among enterprises.

The changing rate of supply chain financial credit risk

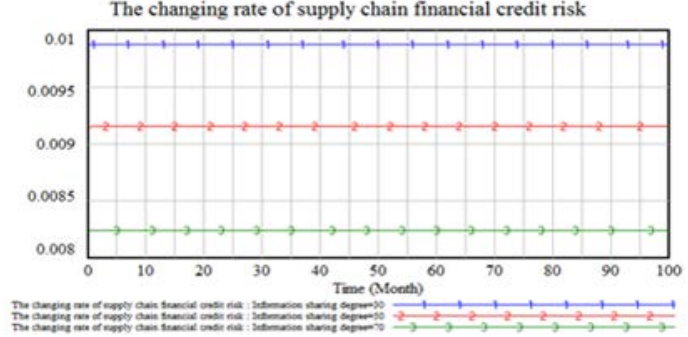

Figure 13: The influence of the information sharing degree on changing rate of supply chain financial credit risk.



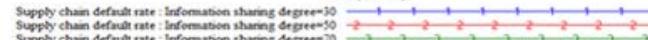

Figure 14: The influence of the information sharing degree on supply chain default rate.

\section{CONCLUSIONS}

This paper established the system dynamics model of Chinese supply chain financial credit risk by using the theory and method of system dynamics, and the simulation is carried out. The influencing factors of Chinese supply chain financial credit risk are divided into internal factors and external factors. The internal factors include supply chain cooperation level, core enterprises credit, SMEs credit, risk awareness of financial institutions and information sharing degree. External factors are mainly the macro-environment and policy. This paper assumed that external factors remain constant and just focused on the internal factors. The simulation results show that when the level of cooperation between core enterprises and SMEs, the basic risk awareness of financial institutions and the degree of information sharing among enterprises are higher, the changing rate of supply chain financial credit risk and the supply chain default rate are lower. The improvement of the credit level of core enterprises and SMEs has certain effect on reducing the credit risk of supply chain finance and supply chain default rate. And compared with SMEs, the influence of core enterprises' credit level on the changing rate of supply chain financial credit risk is more significant.

Through the above simulation analysis, this paper proposed the following suggestions to reduce the Chinese supply chain financial credit risk. Firstly, enterprises should actively improve the cooperation level. Secondly, the financial institutions should improve their own risk consciousness. Thirdly, enterprises should actively improve the credit level and focus on strengthening the credit construction. Fourth, enterprises should further improve information sharing degree and reduce information asymmetry among enterprises, so as to improve the success rate of cooperation and reduce supply chain financial credit risk.

\section{ACKNOWLEDGEMENTS}

This research is supported by the National Natural Science Foundation of China (Grant No. 71701116), Ministry of Education in China Project of Humanities and Social Sciences (Grant No. 15YJC630016) and the Subject of Philosophy and Social Sciences in Shanxi "Research on the construction of credit system in Shanxi Province under the background of Internet finance: credit collection model and assessment support".

\section{REFERENCES}

[1] Lei, L., Shi, J. Z., 2014. Review and Prospect of Supply Chain Finance Theory, East China Economic Management, (6), pp.158-162.

[2] Li, Y. X., 2011. Supply Chain Financial Risk Assessment. Journal of Central University of Finance \& Economics, (10), pp. 36-41.

[3] Peura, H., Yang, S. A., Lai, G., 2016. Trade Credit in Competition: A Horizontal Benefit. Social Science Electronic Publishing, 19(2), pp. 263-289.

[4] Song, H., Yu, K., Ganguly, A., Turson, R., 2016. Supply chain network, information sharing and SME credit quality. Industrial Management \& Data Systems, 116(4), pp.740-758.

[5] Su, Y., Zhong, B., 2017. The Credit Risk Assessment Model of Internet Supply Chain Finance: Multi-Criteria Decision-Making Model with the Principle of Variable Weight. Journal of Computer \& Communications, 04(16), pp.1-11.

[6] Zhu, Y., Xie, C., Sun, B., Wang, G. J., Yan, X. G., 2016. Predicting China's SME Credit Risk in Supply Chain Financing by Logistic Regression, Artificial Neural Network and Hybrid Models. Sustainability, 8(5), pp.433.

[7] Zhu, Y., Xie, C., Wang G. J., Yan, X. G., 2016. Predicting China's SME Credit Risk in Supply Chain Finance Based on Machine Learning Methods. Entropy, 18(5), pp.195. 